\title{
Atratividade docente entre os ingressantes no curso de Pedagogia
}

\author{
SILVA, Kíssila Ferreira Magro da (Brasil, Rio de Janeiro, Campos dos Goytacazes) ${ }^{1 *}$ \\ CORRÊA, Carla Patrícia Quintanilha (Brasil, Rio de Janeiro, Campos dos Goytacazes) ${ }^{2 *}$ \\ ${ }^{1}$ Prefeitura Municipal de Campos dos Goytacazes \\ ${ }^{2}$ Instituto Superior de Educação Professor Aldo Muylaert \\ ORCID ID: https://orcid.org/0000-0002-2766-8890* \\ ORCID ID: http://orcid.org/0000-0001-9934-8151**
}

\begin{abstract}
Resumo
O presente artigo discute a atratividade docente entre os(as) ingressantes no curso de Pedagogia. O objetivo foi conhecer a motivação para o ingresso dos(as) alunos(as) no primeiro período do curso, uma vez que a profissão docente parece estar desvalorizada. $\mathrm{O}$ artigo descreve e analisa o contexto atual da docência, destacando a questão da valorização docente e da atratividade da carreira. Traz ainda os resultados de pesquisa de campo realizada com 65 alunos(as) do primeiro período do curso de Pedagogia de uma instituição estadual em um município do estado do Rio de Janeiro/Brasil, que responderam a um questionário no segundo semestre de 2018. A pesquisa indica que o curso de Pedagogia não era a primeira opção de curso superior da maior parte dos(as) alunos(as), que o escolheram por diversos motivos. Os mais citados foram gostar de trabalhar com crianças e a oportunidade de concluir os estudos.
\end{abstract}

\section{Palavras-chave}

Atratividade docente. Valorização docente. Docência.

\section{Teacher attractiveness of ingressants in Pedagogy course}

\begin{abstract}
This article discusses the attractiveness of teachers among newcomers to the Pedagogy Course. The objective was to know the motivation for students to enter the first period of the course, since the teaching profession seems to be undervalued. The article describes and analyzes the current context of teaching, highlights the issue of teacher appreciation and career attractiveness. It also brings the results of field research conducted with the 65 students of the 1st period of the Pedagogy Course, from a state institution, in a city of Rio de Janeiro / Brazil, who answered a questionnaire in the 2 nd semester of 2018. Research indicates that the Pedagogy Course was not the first college option for most students, who chose it for a variety of reasons. The most cited were: enjoying working with children and the opportunity to complete their studies.
\end{abstract}

\section{Keywords}

Teaching attractiveness. Teacher appreciation. Teaching. 


\title{
Atractividad de la carrera docente entre los ingresantes
}

en el curso de Pedagogía

\begin{abstract}
Resumen
Este artículo discute el atractivo de los docentes entre los recién llegados al curso de Pedagogía. El objetivo era conocer la motivación para que los estudiantes ingresen al primer período del curso, ya que la profesión docente parece estar infravalorada. El artículo describe y analiza el contexto actual de la enseñanza, destaca el tema de la apreciación del maestro y el atractivo profesional. También trae los resultados de la investigación de campo realizada con los 65 estudiantes del primer período del curso de Pedagogía de una institución estatal en una ciudad de Río de Janeiro/Brasil, que respondieron un cuestionario en el segundo semestre de 2018. La investigación indica que el curso de Pedagogía no fue la primera opción universitaria para la mayoría de los estudiantes, que lo eligieron por una variedad de razones. Las más citados fueron: disfrutar trabajando con niños y la oportunidad de completar sus estudios.
\end{abstract}

Palabras clave

Atractivo docente. Apreciación del maestro. Enseñanza.

\section{INTRODUÇÃO}

Optar por um curso superior, escolher uma carreira nem sempre é uma tarefa fácil. Muitas são as opções disponíveis e diversos são os fatores relevantes nesse momento. Além de aptidão ou vocação, são considerados também fatores como a valorização social da profissão, as condições de trabalho, a remuneração, entre outros (CARDOSO; FIGUEIREDO; SOARES, 2016). Além disso, vale ressaltar que determinadas profissões são mais valorizadas pela sociedade. No que diz respeito à carreira docente, é preocupante a significativa diminuição de sua procura pelos concluintes do ensino médio (OLIVEIRA, 2013), que resulta na falta de profissionais docentes em algumas disciplinas.

Essa questão converte-se, portanto, em tema de discussões e artigos acadêmicos e vem sendo debatida também pelos meios de comunicação.

Diante desse quadro, esta pesquisa visa investigar a atratividade docente entre os(as) ingressantes no curso de licenciatura em Pedagogia. O objetivo é conhecer a motivação para o ingresso dos(as) alunos(as) no primeiro período do curso, uma vez que a profissão docente parece estar desvalorizada e possui baixo status social (LOUZANO et al., 2010). Para atingir o objetivo proposto, uma pesquisa de campo foi realizada por meio da técnica de questionário, o qual foi aplicado a estudantes do primeiro período do 
curso de licenciatura em Pedagogia de uma instituição estadual situada em um município do estado do Rio de Janeiro, Brasil. Aceitaram contribuir com o estudo 65 licenciandos(as). A análise das informações colhidas por meio do questionário permitiu tecer algumas considerações sobre a questão da atratividade docente.

O presente trabalho foi organizado em três momentos. Primeiramente, será analisado o contexto atual da docência com seus múltiplos desafios. Após, serão destacadas as questões da valorização docente, remuneração, carreira, condições de trabalho, formação inicial e continuada, além de sua atratividade. Em seguida, serão apresentados os dados colhidos por meio de pesquisa de campo com os(as) alunos(as) do primeiro período do curso de licenciatura em Pedagogia, no segundo semestre de 2018.

Neste estudo, não há a pretensão de exaurir a temática abordada, pois a carreira docente é um assunto extenso, que ainda deixa muito a ser discutido. A expectativa deste trabalho é provocar uma reflexão sobre o tema, para que seja possível uma maior valorização dessa profissão tão relevante para a sociedade.

\section{DOCÊNCIA NO SÉCULO XXI: MÚLTIPLOS DESAFIOS}

Abordar a profissão docente é mencionar um campo de atuação complexo, que se tornou alvo de discussões e reflexões. No Brasil, a questão do preparo de professores surge após a independência, quando começa a haver uma maior preocupação com a instrução popular. A partir daí, a carreira docente passou por diversas transformações ao longo dos últimos dois séculos (SAVIANI, 2009).

Concorda-se com Hagemeyer (2004, p. 70) ao afirmar que "[...] nunca foi tão difícil ser professor como nos dias de hoje". Segundo a autora, "[...] a trajetória da profissão docente tem estreita ligação com a história da educação escolar e com os impasses e desafios por ela enfrentados" e está intimamente ligada também às transformações ocorridas na sociedade ao longo dos anos.

Com a industrialização, o cenário social mundial mudou e tais mudanças se refletiram em vários setores, incluindo o âmbito escolar. De acordo com Dubet (2011), o papel da escola, por exemplo, durante muito tempo foi o de ensinar ao cidadão que ele era membro de uma nação. Cabia ao docente transmitir todo um conjunto de símbolos 
da cultura, ressaltando a cultura nacional. Porém, com as mutações ocorridas em todo o cenário mundial, hoje o docente se vê numa posição de ter que ensinar ao aluno não apenas a cultura nacional, mas também outras culturas que compõem os dias atuais.

Dubet (2011) coloca em discussão como o docente pode passar essa diversidade de conhecimento cultural para seu aluno se muitas vezes nem mesmo ele a possui. Outra questão inquietante ao docente atualmente diz respeito às complexas competências que precisa ajudar o aluno a desenvolver.

Hoje, as competências cidadãs parecem extremamente complexas porque a vida política se divide entre vários níveis, o do município e o da região, o da nação e o da Europa. Ao mesmo tempo, a democracia levou a uma ampla expansão dos direitos culturais e sociais. Para fazer uma escolha política, o cidadão deve estar muito mais informado. (DUBET, 2011, p. 298).

Desse modo, o trabalho docente também se torna mais complexo porque ele necessita ajudar o aluno a compreender suas responsabilidades e direitos. Acaba por ser delegada ao docente a função de formar o educando para a vida em sociedade. $\mathrm{Na}$ concepção Dubet (2011), antes era necessário que a criança soubesse ler, agora, com as modificações ocorridas no mundo, é necessário que a criança esteja preparada também para acompanhar os avanços tecnológicos. Assistir à televisão e navegar na internet se tornaram requisitos essenciais para que um cidadão seja bem informado. De acordo com o autor, "[...] a escola não pode ignorar esse fato e os meios de comunicação estão cada vez mais presentes no ensino" (DUBET, 2011, p. 298).

Há muitos valores, princípios e contradições que se fazem presentes no âmbito escolar e que acabam por se tornar mais um desafio com o qual o professor precisa lidar. Há ainda a questão do objetivo do trabalho desenvolvido na escola. Outrora o objetivo da escola era formar o cidadão, ensiná-lo a ler, escrever e transmitir a ele cultura. Hoje o objetivo da escola é a qualificação desse aluno, é dar-Ihe um diploma, pois "[...] os alunos e seus pais vêm à escola buscar qualificações num mercado de diplomas" (DUBET, 2011, p. 301). Portanto, pode-se considerar que a escola se tornou uma instituição que visa a acordos e contratos. Não se trata mais do ensino em si e de formação cultural, mas de produzir bens e serviços. As instituições escolares tornaram-se uma espécie de mercado (DUBET, 2011). 
Observa-se atualmente uma exigência cada vez maior à escola, responsável por formar um cidadão crítico, consciente de seus direitos e deveres, preparado para acompanhar as novas demandas tecnológicas e preparado, acima de tudo, com os melhores diplomas, com a melhor qualificação para competir pelas melhores vagas.

No entanto, consoante Lantheaume (2012), apesar de as circunstâncias do trabalho docente estarem sendo modificadas e das exigências serem cada vez maiores, nem sempre recursos necessários são oferecidos para que o trabalho seja desenvolvido apropriadamente. Pode-se dizer que "[...] as dificuldades dos professores estão ligadas muito mais ao ambiente de trabalho do que a transtornos pessoais que eles levariam para a sala de aula" (LANTHEAUME, 2012, p. 372).

Faltam incentivos para preparar o docente a corresponder às novas demandas da carreira, de modo que, buscando sanar o desassossego causado pelas múltiplas expectativas em relação ao seu trabalho, muitos vêm buscando novas soluções para lidar com os problemas que surgem no dia a dia, "[...] visando a controlar as situações, restaurar uma autoestima maltratada, compensar uma perda de energia, certo desengajamento e falta de reconhecimento" (LANTHEAUME, 2012, p. 373).

Porém, algumas das estratégias utilizadas para lidar com o cotidiano da profissão são um tanto defensivas. De acordo com Lantheaume (2012, p. 375), para lidar com as agressões, as decepções, as incertezas e as adversidades, muitos professores optam por se endurecer ou, como mencionado por um professor entrevistado pela autora, "É preciso se blindar", de modo que seja possível suportar os imprevistos que surgem na profissão e para continuar o trabalho mesmo em face de dificuldades.

Trata-se de resignação, de se conformar com o problema, uma vez que encontrar uma solução parece impossível. O que resta ao docente é continuar trabalhando mesmo diante de dificuldades, mas também há aqueles docentes que, mesmo diante das dificuldades, não se conformam com o fracasso e com o sentimento de inutilidade. Esses optam por adaptar seu trabalho, de modo a desempenhá-lo do melhor modo possível. Para esses, torna-se necessário "[...] adaptar a regra, modificá-la, relativizá-la, reinterpretá-la, criar outras regras, negociar as situações e as normas em uma perspectiva pragmática, eis uma das principais saídas dos professores perante as provas do trabalho" (LANTHEAUME, 2012, p. 377). 
Desse modo, esses docentes buscam melhorar suas aulas, propondo ferramentas e atividades que podem lhes ajudar a contornar alguns problemas. Nas palavras de Lantheaume (2012, p. 379), isso requer "[...] disposição de espírito e a energia exigidas para criar essas atividades", o que pode resultar em um processo de desgaste ao longo do tempo.

Vários estudos têm buscado analisar a temática da docência na atualidade investigando os cursos de formação de professores, incluindo o curso de licenciatura em Pedagogia, que constituiu o foco da presente pesquisa (BARRETO, 2015; GATTI, 2010, 2014; GONÇALVES, 2017; MARIN; GIOVANNI, 2013; PIMENTA et al., 2017; SARTI, 2019). De modo geral, esses estudos revelam que o perfil do alunado que busca o curso de Pedagogia é majoritariamente feminino (MARIN; GIOVANNI, 2013), possui jornada dupla de trabalho e estudo, com deficiências formativas provenientes da escola pública (GATTI, 2014), optando, muitas vezes, pelos cursos a distância (BARRETO, 2015) ou mesmo presenciais, mas que também apresentam fragilidades em sua matriz curricular (GATTI, 2010; PLACCO; SOUZA; ALMEIDA, 2012; PIMENTA et al., 2017).

Diante dessa conjuntura, a desvalorização da profissão docente se estabelece no cenário da sociedade atual, contribuindo para que os jovens egressos do ensino médio não queiram escolher a carreira docente.

\section{VALORIZAÇÃO DOCENTE E ATRATIVIDADE}

Sob a óptica de Oliveira (2013), a valorização dos profissionais da educação é temática muito presente no debate educacional brasileiro. Portanto, ao falar de carreira, destaca três elementos importantes que interferem na condição desse profissional, a saber: 1) a remuneração, 2) a carreira e condição de trabalho e 3) a formação inicial e continuada. Quanto à valorização dos profissionais da educação, a Lei de Diretrizes e Bases da Educação Nacional (LDBEN), de 1996, no artigo 67, destaca que:

Os sistemas de ensino promoverão a valorização dos profissionais da educação, assegurando-Ihes, inclusive nos termos dos estatutos e dos planos de carreira do magistério público: I - ingresso exclusivamente por concurso público de provas e títulos; II - aperfeiçoamento profissional continuado, inclusive com licenciamento periódico remunerado para esse fim; III- piso salarial profissional; IV - progressão funcional baseada na titulação ou habilitação, e na avaliação do desempenho; V - período

Educação \& Formação, Fortaleza, v. 5, n. 13, p. 59-78, jan./abr. 2020

DOI: https://doi.org/10.25053/redufor.v5i13.1468

http://seer.uece.br/redufor 
reservado a estudos, planejamento e avaliação, incluído na carga de trabalho; VI - condições adequadas de trabalho.

A promulgação dessa lei representou uma grande conquista para os profissionais da educação, demonstrando que a temática da valorização desses profissionais e sua condição de trabalho mereciam atenção.

Em 16 de julho de 2008, foi promulgada a Lei № 11.738, que trata especificamente da remuneração (MASSON, 2017). Essa lei estabelece o Piso Nacional do Magistério, representando uma importante conquista para a valorização docente. Porém, apesar de haver leis que norteiem e garantam tal valorização, elas não se mostraram suficientes para que os profissionais da educação de fato se sentissem valorizados. Masson (2017, p. 856) assinala que isso ocorre porque:

Embora exista regulamentação para a organização dos planos de carreira dos professores, essa se dá de forma muito variada, com uma diversidade de critérios e formatos que dificultam a definição dos requisitos mínimos indispensáveis para a carreira docente e a garantia de uma adequada valorização dos professores.

Os planos de carreira são adequados às características dos docentes e suas redes estaduais e municipais, de modo que há, de um estado para o outro, significativas diferenças referentes aos salários e ao cumprimento do piso salarial. Observa-se que não há critérios para igualar os salários e os requisitos mínimos para garantir a devida valorização dos docentes.

As condições de trabalho também foram contempladas na vigente LDBEN, Lei no 9.394/1996, mas há ainda muito o que se refletir sobre isso. Segundo Bauer, Cassetari e Oliveira (2017), são muitos os problemas que levam os professores a afirmarem que essa profissão está desvalorizada. Além da baixa remuneração, há outros aspectos das condições do trabalho docente que merecem atenção, como o clima no trabalho, a violência e a sensação de insegurança, as expectativas altas de pais e governantes e a escassa oportunidade de crescimento pessoal.

Outro aspecto que deve ser considerado diz respeito ao aumento das exigências para a atividade docente na atualidade. $O$ trabalho do professor está cada vez mais complexo e exige responsabilidades cada vez maiores, seja no que se refere às atividades pedagógicas propriamente ditas, seja em razão de questões que extrapolam a mediação com o conhecimento, como a violência e as drogas. (TARTUCE et al., 2010, p. 449). 
Além do que já foi mencionado, Tartuce et al. (2010) destacam que a falta de organização e materiais nas escolas e a falta de interesse em aprender de alguns alunos são fatores que contribuem para o desgaste docente e para que alguns acreditem que a carreira docente é muito trabalhosa e não compensa.

Consoante Louzano et al. (2010), outros países atraem as pessoas para a carreira docente por oferecerem bons salários e investirem em uma formação de qualidade. No Brasil, além de os salários serem motivo de questionamentos dos docentes, observa-se que os que ingressam na formação docente são, muitas vezes, aqueles menos preparados.

A literatura indica que a profissão tem atraído a parcela da população com menor background cultural e econômico. É pouco provável que, no Brasil, a curto prazo, consiga se melhorar a qualidade dos professores por meio da atratividade de alunos com melhor perfil cultural $e$ econômico. A alternativa é levar em conta esse fato para modelar os cursos de formação, procurando superar as lacunas de formação básica. (BAUER; CASSETARI; OLIVEIRA, 2017, p. 947).

De acordo com Louzano et al. (2010, p. 553), outros países do mundo "[...] empenham-se em não só oferecer formação de qualidade aos professores iniciantes, mas também oportunidades e incentivos para o desenvolvimento profissional contínuo ao longo da sua carreira", o que infelizmente não ocorre no Brasil, fazendo com que os concluintes do ensino médio não encontrem muitos incentivos para optarem pela docência (LOUZANO et al., 2010).

Louzano et al. (2010, p. 554) continuam ressaltando que em outros países a "[...] interação dos futuros professores com a escola é intensa. Preparação de aulas, aulas práticas, estratégias para ensinar alunos com dificuldades de aprendizagem são parte importante do curso de formação docente". No Brasil, a interação dos licenciandos com a escola é bem pequena, não sendo suficiente para prepará-los para o dia a dia de um docente. Além disso, Tartuce et al. (2010) ainda discutem o fato de a carreira docente ter se tornado pouco seletiva, pois muitos docentes exercem sua profissão sem preparo suficiente, o que contribui para que as pessoas acreditem que qualquer um pode ser professor, mesmo sem formação específica.

Há também alguns fatores considerados atrativos em relação à formação docente. Dentre eles, Louzano et al. (2010) destacam a flexibilidade, as férias, as baixas taxas de 
desemprego e o altruísmo como atrativos. Segundo os autores, entre as vantagens em ser professor, está a flexibilidade, pois a maioria dos professores tem opção de adaptar seu trabalho às necessidades pessoais e financeiras. Existe na profissão docente a opção de escolher trabalhar em tempo integral ou parcial e atuar em diversos trabalhos. Além disso, geralmente as férias do docente são mais longas do que a de outros profissionais, pois acompanham as férias escolares. Outro fator a ser levado em consideração é a possibilidade de concurso público na área. Segundo pesquisa realizada por Corrêa et al. (2019, p. 133), esse pode ser o fator que faz com que a docência seja atrativa para alguns alunos, pois buscam "[...] as garantias do serviço público".

As baixas taxas de desemprego também constituem fator atrativo à profissão docente (LOUZANO et al., 2010), além do altruísmo, pois muitos optam pela carreira docente acreditando que, de alguma forma, podem contribuir para o desenvolvimento da sociedade. Porém, de acordo com Cardoso, Figueiredo e Soares (2016, p. 33), apesar de a docência ser "[...] uma profissão com profundo sentido e compromisso humano", não deixa de ser em toda sua extensão uma profissão. Por isso, ao escolher uma carreira, muitos optam por aquelas que demonstram ser mais bem remuneradas e valorizadas. Infelizmente os fatores não atrativos à carreira docente superam os que são atrativos, levando, portanto, a uma significativa diminuição da procura desses cursos. Diante do exposto, foi realizada uma pesquisa de campo buscando sondar essas questões.

\section{ANALISANDO OS DADOS DA PESQUISA DE CAMPO}

A pesquisa foi realizada nas turmas de primeiro período do curso de licenciatura em Pedagogia de uma instituição estadual em um município do estado do Rio de Janeiro, Brasil. No segundo semestre de 2018, o curso contava com três turmas de primeiro período, totalizando 150 alunos(as) matriculados(as). Desses, 65 aceitaram disponibilizar seu tempo para preencher um questionário. De acordo com relatos de alguns(mas) professores(as), nem todos(as) os(as) 150 matriculados(as) frequentavam o curso à época da pesquisa.

O questionário aplicado contou com 12 questões, sendo três delas de múltipla escolha, três fechadas e seis abertas. O instrumento foi elaborado com o intuito de obter informações que permitissem uma caracterização desse(a) aluno(a) que optou pelo 
curso de Pedagogia, incluindo faixa etária, se trabalhavam, se este curso havia sido sua primeira opção de curso superior e o porquê da escolha. A análise das informações colhidas através do questionário permitiu tecer algumas considerações.

Constatou-se que $28 \%$ dos(as) alunos(as) que responderam ao questionário possuíam então menos de 20 anos, 55\% apresentavam de 20 a 30 anos, 9\% estavam na faixa etária de 31 a 40 anos e 8\% tinham acima de 40 anos. Levando em consideração que a idade esperada para a conclusão do ensino médio é de 17 anos, pode-se concluir que o curso de Pedagogia parece não ter sido a opção escolhida por alunos(as) que concluíram o ensino médio recentemente, corroborando os achados de Louzano et al. (2010).

Verificou-se ainda que $34 \%$ dos(as) respondentes conciliavam o trabalho com o curso de Pedagogia, enquanto 66\% encontravam-se sem trabalho no momento da pesquisa, o que leva a pensar que, para eles(as), o curso em questão pode ser uma oportunidade de se inserir no mercado de trabalho. Esses dados diferem daqueles apresentados por Gatti (2014), que revelam que a maioria dos(as) licenciandos(as) exerce algum tipo de ocupação enquanto estudam, diminuindo seu tempo de dedicação ao curso. No caso da maioria dos(as) licenciandos(as) da presente pesquisa, parece haver maior possibilidade de dedicação às atividades do curso de Pedagogia.

Em relação aos(às) licenciandos(as) que estavam trabalhando, constatou-se que os(as) 22 respondentes atuavam em diversas áreas. Havia quem trabalhasse como secretária, recepcionista, confeiteira, costureira, babá, doméstica, auxiliar de escritório, auxiliar de secretaria, auxiliar contábil, comerciário, em panfletagem, em farmácia e também em ambiente escolar, como auxiliar de turma e professor. Dois(Duas) licenciandos(as) mencionaram trabalhar em uma universidade estadual no município, mas não mencionaram em que função.

As respostas a essa questão fazem refletir sobre a possibilidade de o curso de Pedagogia ser uma oportunidade de adquirir aperfeiçoamento para aqueles que já atuam em ambiente escolar e como uma oportunidade de atuar numa diversidade maior de áreas para aqueles que possuem as mais variadas profissões.

Perguntados se o curso de Pedagogia havia sido primeira opção de curso superior, 45 dos(as) respondentes (69\%) responderam que não. Apenas 20 alunos(as) (31\%) consideraram esse curso como primeira opção de curso superior. Esses dados confirmam a afirmação de Oliveira (2013) de que o magistério é uma segunda opção 
para muitos. Isso ficou ainda mais evidente quando esses(as) alunos(as) que afirmaram que o curso de Pedagogia não havia sido sua primeira opção foram questionados quanto a qual teria sido a primeira opção. Constatou-se que não seriam muitos(as) os(as) que optariam pela carreira docente. A primeira opção de dois(duas) dos(as) respondentes seria a licenciatura em Geografia; um(a), licenciatura em História; um(a), licenciatura em Biologia; um(a), licenciatura em Química; três, licenciatura em Matemática; e três fariam Educação Física, somando, assim, 11 alunos(as) que escolheriam a carreira docente, ou seja, apenas $17 \%$ do total de respondentes.

Os(As) outros(as) 34 discentes - do total de 45 - que não optariam pelo curso de Pedagogia, ao responderem sobre sua primeira opção de curso superior, mencionaram diversas áreas, como: Administração, Serviço Social, Psicologia, Direito, Arquitetura, Estética, Medicina, Veterinária, Enfermagem, Design Gráfico, Recursos Humanos, Nutrição, Publicidade, Fisioterapia e Engenharia, tendo maior destaque o curso de Psicologia, que foi a primeira opção de oito estudantes. Dois(Duas) dos(as) respondentes mencionaram que não tinham apenas uma primeira opção, mas duas. Um(a) mencionou que gostaria de ter cursado Medicina ou Direito, outro(a) optaria por Direito ou Psicologia, de modo que, nesses casos, o curso de licenciatura em Pedagogia não era nem mesmo uma segunda opção.

Segundo Tartuce et al. (2010), muitos julgam não possuir as características necessárias à docência, além de não a considerarem uma profissão valorizada. Por isso, de acordo com Masson (2017), a procura por bacharelado é três vezes maior do que a do curso de Pedagogia e as licenciaturas, pois, para muitos, essas profissões são mais valorizadas e bem remuneradas do que a profissão docente. Escolher a docência é estar sujeito a um possível estado de desassossego (LANTHEAUME, 2012).

Quando questionados(as) se o curso de Pedagogia era o primeiro curso de ensino superior que faziam, $86 \%$ dos(as) alunos(as) responderam que sim; apenas $14 \%$ responderam que já haviam cursado outro curso superior; dois(duas) licenciandos(as) haviam cursado Matemática, um(a) Química, um(a) Biologia, um(a) Psicologia, um(a) Gastronomia, um(a) Administração, um(a) Ciências Contábeis e um(a) Engenharia de Produção, mas, como já mencionado, a maior parte dos(as) respondentes encontrava-se no primeiro curso superior. 
Perguntados sobre como eles(as) ficaram sabendo do curso de Pedagogia da instituição pesquisada, verificou-se que 25 souberam por meio de amigos, 16 pelas redes sociais, seis por parentes, quatro pela televisão ou outra mídia, 12 por outros meios e dois por dois meios diferentes, como ilustra a Tabela 1.

Tabela 1 - Como ficaram sabendo do curso

\begin{tabular}{l|c}
\hline \multicolumn{1}{c|}{ Ficaram sabendo do curso... } & № de participantes \\
\hline Por meio de amigos & 25 \\
\hline Pelas redes sociais & 16 \\
\hline Por meio de parentes & 6 \\
\hline Pela televisão ou outra mídia & 4 \\
\hline Outros & 12 \\
\hline${ }^{*}$ Marcaram duas opções & 2 \\
\hline \multicolumn{2}{c}{ Fonte: Elaboração própria (2019). }
\end{tabular}

Dos(as) 12 que assinalaram a opção "outros", a Tabela 2 apresenta os outros meios pelos quais os(as) participantes ficaram sabendo do curso.

Tabela 2 - Outros meios

\begin{tabular}{l|c}
\hline \multicolumn{1}{c|}{ Outros meios } & № de participantes \\
\hline Exame Nacional do Ensino & \\
Médio ou Sistema de Seleção \\
Unificada (Sisu)
\end{tabular}

Fonte: Elaboração própria (2019).

Dos(as) que assinalaram duas opções, um afirmou que tinha ouvido sobre o curso por amigos e pelas redes sociais e um por amigos e na própria instituição, pois já tinha sido aluno(a) nela.

Perguntados sobre o porquê terem escolhido o curso de Pedagogia, constatou-se que muitos tinham sido os motivos. Para quatro participantes da pesquisa, trabalhar como professor era um sonho. "É um sonho de infância. Sempre quis cursar Pedagogia para trabalhar com criança na educação infantil. Na minha infância, minha brincadeira era de escolinha", relatou um(a) dos(as) alunos(as).

Quatro respondentes afirmaram se identificar com a área e acreditar que ser pedagogo é sua vocação. Esses(as) podem se identificar com Tartuce et al. (2010), que afirmam que algumas pessoas julgam que há um certo prazer em ser professor. 
Segundo os autores, para tais pessoas, parece ser gratificante contribuir com a aprendizagem de outros.

Outro fator mencionado foi a influência familiar, evidenciada na resposta dada por esses(as) alunos(as): “Tenho gente na família que é pedagogo e me deu força para fazer também"; "Escolhi o curso por influência da minha mãe". Outros(as) quatro respondentes mencionaram que este havia sido o motivo que os(as) tinha levado a optar pelo curso de Pedagogia: ouvir relatos de familiares que são professores, além do incentivo desses familiares.

Outro fator mencionado por muitos(as) dos(as) discentes para terem escolhido o curso de Pedagogia foi a oportunidade de continuação dos estudos: 11 responderam que haviam feito o curso normal superior e tinham visto nesse curso uma forma de aprofundar seu conhecimento e dar continuidade à sua formação.

Houve também aqueles(as) que tinham escolhido o curso baseados no mercado de trabalho. Como apresentado anteriormente, consoante Louzano et al. (2010), um dos fatores atrativos da carreira docente é a baixa taxa de desemprego, pois professores raramente ficam muito tempo desempregados. Para seis alunos(as) participantes da pesquisa, esse foi o fator decisivo ao fazer sua escolha. Para eles(as), é fácil conseguir um emprego na área. Isso ficou evidenciado na fala de um(a) dos(as) alunos(as) ao explicar por que haviam escolhido o curso: "Escolhi por ser uma profissão que proporciona emprego".

Houve ainda 11 alunos(as) que gostariam de ter feito outro curso. Esses(as) mencionaram que haviam feito o Enem e que, com a nota que haviam obtido, não tinha sido possível matricular-se no curso que gostariam, de modo que o curso de licenciatura em Pedagogia havia sido a opção disponível. "Foi o que deu para fazer com minha nota do Enem", relatou um(a) dos(as) respondentes. "Resolvi abraçar a oportunidade que me apareceu, pois queria muito estudar". De acordo com Tartuce et al. (2010), a motivação de algumas pessoas que ingressam no magistério está no campo dos valores altruístas e realização pessoal. Muitos escolhem a carreira docente por gostarem de ensinar e trabalhar com crianças. Isso foi confirmado nesta pesquisa ao se verificar que 15 alunos(as) haviam escolhido esse curso por gostarem de trabalhar com crianças e na área de educação, sete disseram que cursar Pedagogia Ihes proporcionava realização 
pessoal e/ou profissional e três afirmaram que Ihes seria possível entender o processo de aprendizagem das crianças e esse conhecimento Ihes seria útil no dia a dia.

Uma vez que, de acordo com as Diretrizes Curriculares Nacionais para o curso de graduação em Pedagogia, licenciatura (Resolução CNE/CP no 1/2006), o pedagogo é um profissional com a possibilidade de atuar em vários ambientes ${ }^{1}$, os(as) alunos(as) foram questionados(as) sobre a área em que pretendiam atuar. Muitos(as) só descobriram que 0 curso de Pedagogia permite trabalhar em vários ambientes após ingressarem no curso. Esse pode ser o motivo que levou 21 dos(as) respondentes a marcarem três ou mais opções quanto ao ambiente em que pretendiam atuar. Isso leva a refletir que esses(as) licenciandos(as) esperam que o curso Ihes abra novas possibilidades de atuar em diversas áreas. A Tabela 3 apresenta a frequência da escolha profissional dos(das) participantes. Dos(as) três licenciandos(as) que assinalaram a opção "outros", um(a) desejava trabalhar como professor(a) universitário(a), um(a) desejava trabalhar na secretaria de uma escola e um(a) desejava ser pedagogo(a) no Exército ou outra Força Armada.

Tabela 3 - Frequência de escolha profissional

\begin{tabular}{l|c}
\multicolumn{1}{c|}{ Opção } & Frequência \\
\hline Professor(a) de crianças de 0 a 5 anos & 31 \\
\hline Professor(a) de crianças 1ํ ao 5 ano do ensino fundamental & 24 \\
\hline Coordenador(a) pedagógico de uma escola & 28 \\
\hline Diretor(a) de uma escola & 17 \\
\hline Pedagogo(a) de um hospital & 8 \\
\hline Pedagogo(a) em abrigos & 9 \\
\hline Pedagogo(a) em uma empresa & 13 \\
\hline Outros & 3 \\
\hline
\end{tabular}

Fonte: Elaboração própria (2019).

Ao observar a Tabela 3, é possível notar que a maioria dos(as) licenciandos(as) pretende atuar em ambiente escolar e, nesse sentido, grande parte optaria por trabalhar como professor(a) de crianças de 0 a 5 anos. Segundo Corrêa et al. (2019, p. 137), o motivo de tal preferência pode ser a "[...] ideia corrente no senso comum, que aponta o trabalho do professor de educação infantil como o mais simples de ser realizado devido à idade das crianças". Essa ideia desconsidera o fato de que o trabalho na educação infantil

\footnotetext{
1 "As Diretrizes Curriculares para o curso de Pedagogia aplicam-se à formação inicial para o exercício da docência na Educação Infantil e nos anos iniciais do Ensino Fundamental, nos cursos de Ensino Médio, na modalidade Normal, e em cursos de Educação Profissional na área de serviços e apoio escolar, bem como em outras áreas nas quais sejam previstos conhecimentos pedagógicos" (BRASIL, 2006, art. $2^{\circ}$ ).
}

Educação \& Formação, Fortaleza, v. 5, n. 13, p. 59-78, jan./abr. 2020

DOI: https://doi.org/10.25053/redufor.v5i13.1468

http://seer.uece.br/redufor 
pode ser muito mais complexo, pois exige que o docente desenvolva diariamente um trabalho que contemple os vários aspectos do desenvolvimento infantil, não apenas o cognitivo, mas também o aspecto físico, emocional, dentre outros.

Outro aspecto a destacar acerca da Tabela 3 é o quantitativo expressivo de licenciandos(as) que desejam atuar em atividades de gestão e coordenação pedagógica em escolas. Esse é um ponto importante de reflexão sobre o curso de Pedagogia, uma vez que pesquisas indicam fragilidades na formação do pedagogo que atuará nessas áreas (PIMENTA et al., 2017; PLACCO; SOUZA; ALMEIDA, 2012). Da mesma forma, o quantitativo de licenciandos(as) que intencionam atuar fora do ambiente escolar também é expressivo. Sobre essa questão, Pimenta et al. (2017) alertam, a partir dos dados do seu estudo, que a matriz curricular do curso de Pedagogia ainda se mostra frágil diante da necessária preparação do pedagogo para atuar em espaços não escolares. Sendo assim, os cursos de Pedagogia necessitam problematizar urgentemente essa questão, que envolve não só a discussão de material teórico apropriado, mas também o ingresso dos(as) licenciandos(as) em espaços não escolares para desenvolverem o estágio.

Os(As) licenciandos(as) foram questionados ainda quanto aos requisitos necessários para que a profissão do pedagogo seja valorizada. De acordo com os(as) respondentes desta pesquisa, existem vários fatores essenciais para a valorização do pedagogo. Segundo nove dos(das) respondentes, uma forma de fazer isso é oferecer uma formação que os prepare melhor para o exercício da função docente, uma formação que contemple teoria e prática. Além disso, fazem-se necessários programas para a continuação da formação desses profissionais, "[...] políticas públicas que priorizem a educação e a formação continuada para professores" foram os requisitos citados por um(a) dos(as) alunos(as).

Nas palavras de Corrêa et al. (2019, p. 137), "[...] são necessárias políticas públicas voltadas à valorização docente, objetivando recuperar a atratividade para a carreira". Faz-se mister que as políticas públicas sejam modificadas para que reconheçam a importância e complexidade do trabalho docente, pois envolve muito mais do que ensinar a ler e escrever, envolve também compreender cada etapa da educação básica para que se desenvolva um trabalho pedagógico capaz de contribuir com os múltiplos aspectos envolvidos no desenvolvimento da criança.

Educação \& Formação, Fortaleza, v. 5, n. 13, p. 59-78, jan./abr. 2020 
Outro requisito citado pelos(as) alunos(as) para que essa valorização ocorra é o respeito e o reconhecimento da importância do profissional da Pedagogia pela sociedade. Dos(as) participantes, 22 mencionaram esse como um fator de grande importância. Isso ficou evidenciado na fala destes(as) alunos(as): "A valorização do professor, ou seja, o reconhecimento da importância dos pedagogos e dos professores em geral na sociedade"; outro(a) mencionou: "Ser respeitado, as pessoas colocarem essa profissão em primeiro lugar, e não em último"; e ainda um(a) dos(as) respondentes citou: "Que as pessoas entendam o valor do educador e ensinem as crianças e jovens a valorizar e respeitar esse profissional essencial para todos".

Ainda outros requisitos foram destacados pelos(as) participantes da pesquisa: 15 mencionaram melhores salários, condições de trabalho adequadas e suporte para as escolas. De acordo com dados apresentados por estudo feito por Hirata, Oliveira e Mereb (2019, p. 199), "[...] os professores recebem, em média, menos que outros profissionais com educação superior no Brasil". Isso faz com que muitos desistam da carreira docente e se sintam desvalorizados, pois julgam que a remuneração que recebem não condiz com o trabalho que desenvolvem. Houve ainda seis licenciandos(as) que responderam que o amor pela profissão e a dedicação ao que faziam era suficientes para se sentirem profissionais valorizados(as); sete mencionaram a importância de haver políticas públicas que priorizem a educação, além de reconhecimento por parte dos governantes da importância do pedagogo; e seis não disseram o que seria necessário para que de fato ocorra essa valorização.

Sobre a expectativa dos(as) alunos(as) com o curso de Pedagogia, sete responderam que sua expectativa era conseguir emprego na área de educação, mostrando, assim, novamente que a opção pelo curso pode ter sido feita baseada no mercado de trabalho, por muitos acreditarem ser fácil conseguir emprego. Apenas um(a) aluno(a) mencionou que sua expectativa com o curso também era de se inserir no mercado profissional, porém, diferentemente dos(as) outros(as) sete, esse(a) discente não desejava trabalhar na área de educação, optando pelo ambiente empresarial ou hospitalar.

A maioria dos(as) respondentes, 19 alunos(as), mencionou que sua expectativa com o curso era a de ampliar e aprimorar seus conhecimentos na área de educação e 14 suscitaram que sua expectativa era a de um dia poder contribuir com seu trabalho para a 
formação e aprendizagem de outros. Isso aponta para a colocação de Tartuce et al. (2010) de que a escolha pela profissão docente é motivada por valores altruístas, envolve o desejo de ensinar e a possibilidade de contribuir de alguma forma.

Houve ainda outras expectativas relacionadas ao curso de Pedagogia: nove respondentes mencionaram que esperavam concluir a formação superior, sete mencionaram que estavam gostando muito do curso, por isso as expectativas eram as melhores possíveis, três tinham a expectativa de serem reconhecidos(as) e terem prestígio após a formação em Pedagogia e cinco não possuíam nenhuma expectativa com o curso ou não sabiam responder por ainda não terem pensado sobre 0 assunto.

\section{CONSIDERAÇÕES FINAIS}

Neste artigo, buscou-se contribuir com o debate sobre a atratividade do curso de licenciatura em Pedagogia. $O$ objetivo foi conhecer os motivos para o ingresso dos(as) alunos(as) no primeiro período do curso. Os resultados da pesquisa de campo apontaram que a maior parte dos que haviam ingressado no curso não tinham mais do que 30 anos, estando em sua maioria desempregados(as), esperando com o curso ter uma oportunidade de se inserir no mercado de trabalho ou, no caso dos(as) que estavam empregados(as), adquirir mais conhecimento e aperfeiçoamento para atuar em outras áreas.

Os dados também indicam que mais da metade dos(as) participantes não tinham o curso de Pedagogia como primeira opção de curso superior, mas que, mesmo assim, não haviam tido a oportunidade de ingressar no outro curso pretendido. Quando questionados(as) quanto ao porquê da escolha pelo curso, observou-se que diversos foram os motivos que os(as) haviam levado a cursar Pedagogia, porém os mais citados foram o gosto por trabalhar com crianças e a oportunidade de concluir os estudos.

Por meio da análise dos dados, foi possível apontar que a maior parte dos(as) graduandos(as) estava gostando muito do curso, que era para eles(as) uma oportunidade de se aprimorar e contribuir para a aprendizagem de outros. Mesmo aqueles(as) que haviam optado por outro curso superior, mostraram-se animados(as) com o curso de Pedagogia, mas estavam conscientes de que o dia a dia de um pedagogo pode não ser fácil e que muito pode ser feito para que esse profissional seja mais valorizado. 
Esses dados provocam a reflexão sobre os desafios formativos enfrentados pelo Curso de Pedagogia na atualidade, na medida em que necessita contemplar um corpo discente que não queria ingressar na docência, mas diante da falta das opções desejadas, aceitou nele se engajar. A partir daí, os dados revelam um aparente gosto pelas atividades do curso e pelas oportunidades de inserção profissional trazidas pela nova área abraçada.

Entretanto, é importante ressaltar que a responsabilidade da formação do pedagogo é significativa, tendo em vista que os estudos aqui mencionados evidenciam fragilidades nas propostas formativas, especialmente na atuação na gestão educacional e em espaços não escolares. Diante desses aspectos, há urgência na reflexão coletiva quanto a esses e outros desafios enfrentados pelo curso de Pedagogia na contemporaneidade.

Finalmente, este estudo não teve a pretensão de exaurir a temática abordada, pois a carreira docente é um assunto extenso, que ainda deixa muito a ser discutido. $O$ intuito foi provocar uma reflexão sobre a temática abordada, uma vez que, embora o curso de licenciatura não tenha sido a primeira opção de seus ingressantes, os dados aqui coletados indicam envolvimento dos(as) licenciandos(as) com o curso de Pedagogia, mesmo cientes da desvalorização docente enfrentada no país.

\section{REFERÊNCIAS}

BARRETO, E. S. S. Políticas de formação docente para a educação básica no Brasil: embates contemporâneos. Revista Brasileira de Educação, Rio de Janeiro, v. 20, n. 62, p. 679-701, 2015.

BAUER, A.; CASSETARI, N.; OLIVEIRA, R. P. Políticas docentes e qualidade da educação: uma revisão de literatura e indicações de política. Ensaio: Avaliação e Políticas Públicas em Educação, Rio de Janeiro, v. 25, n. 97, p. 943-970, 2017.

BRASIL. Lei o 9.394, de 20 de dezembro de 1996. Estabelece as Diretrizes e Bases da Educação Nacional. Diário Oficial [da] República Federativa do Brasil, Poder Executivo, Brasília, DF, 21 dez. 1996.

BRASIL. Lei $n^{\circ} 11.738$, de 16 de julho de 2008. Regulamenta a alínea "e" do inciso III do caput do art. 60 do Ato das Disposições Constitucionais Transitórias, para instituir o piso salarial profissional nacional para os profissionais do magistério público da educação básica. Diário Oficial [da] República Federativa do Brasil, Poder Executivo, Brasília, DF, 17 jul. 2008. 
BRASIL. Resolução CNE/CP no 5, de 13 de dezembro de 2005. Diretrizes Curriculares Nacionais para o Curso de Pedagogia. Diário Oficial [da] República Federativa do Brasil, Poder Executivo, Brasília, 16 maio 2006.

CARDOSO, M. C.; FIGUEIREDO, S. O.; SOARES, S. E. C. Atratividade da carreira docente na educação básica: Fios de reflexões sobre o prazer e o sofrimento da professoralidade. Revista de Iniciação à Docência, Vitória da Conquista, v. 1, n. 1, p. 2536, 2016.

CORRÊA, C. P. Q. et al. A atratividade da docência na educação infantil em ingressantes do curso de Pedagogia. Educação: Teoria e Prática, Rio Claro, v. 29, n. 60, p. 121-139, 2019.

DUBET, F. Mutações cruzadas: a cidadania e a escola. Revista Brasileira de Educação, Rio de Janeiro, v. 16, n. 47, p. 289-322, 2011.

GATTI, B. A. Formação de professores no Brasil: características e problemas. Educação e Sociedade, Campinas, v. 31, n. 113, p. 1355-1379, 2010.

GATTI, B. A. Formação inicial de professores para a educação básica: pesquisas e políticas educacionais. Estudos em Avaliação Educacional, São Paulo, v. 25, n. 57, p. 24-54, 2014.

GONÇALVES, S. R. V. O curso de Pedagogia no Brasil: da formação específica para a formação generalista. Revista Espaço do Currículo, João Pessoa, v. 10, n.2, p. 244-258, 2017.

HAGEMEYER, R. C. C. Dilemas e desafios da função docente na sociedade atual: os sentidos da mudança. Educar, Curitiba, n. 24, p. 67-85, 2004.

HIRATA, G.; OLIVEIRA, J. B. A.; MEREB, T. M. Professores: quem são, onde trabalham, quanto ganham. Ensaio: Avaliação e Políticas Públicas em Educação, Rio de Janeiro, v. 27, n. 102, p. 179-203, 2019

LANTHEAUME, F. Professores e dificuldades do ofício: preservação e reconstrução da dignidade profissional. Cadernos de Pesquisa, São Paulo, v. 42, n. 146, p. 368-387, 2012.

LOUZANO, P. et al. Quem quer ser professor? Atratividade, seleção e formação docente no Brasil. Estudos em Avaliação Educacional, São Paulo, v. 21, n. 47, p. 543-568, 2010.

MARIN, A. J.; GIOVANNI, L. Formação de professores para o início da escolarização: fragilidades. Intermeio, Campo Grande, v. 19, n. 38, p. 52-68, 2013.

MASSON, G. Requisitos essenciais para a atratividade e a permanência na carreira docente. Educação \& Sociedade, Campinas, v. 38, n. 140, p. 849-864, 2017.

OLIVEIRA, D. A. As políticas de formação e a crise da profissionalização docente: por onde passa a valorização? Revista Educação em Questão, Natal, v. 46, n. 32, p. 51-74, 2013.

Educação \& Formação, Fortaleza, v. 5, n. 13, p. 59-78, jan./abr. 2020

DOI: https://doi.org/10.25053/redufor.v5i13.1468

http://seer.uece.br/redufor 
PIMENTA, S. G. et al. Os cursos de licenciatura em Pedagogia: fragilidades na formação inicial do professor polivalente. Educação e Pesquisa, São Paulo, v. 43, n. 1, p. 15-30, 2017.

PLACCO, V. M. N. S.; SOUZA, V. L. T.; ALMEIDA, L. R. O coordenador pedagógico: aportes à proposição de políticas públicas. Cadernos de Pesquisa, São Paulo, v. 42, n. 147, p. 754-771, 2012.

SARTI, F. M. O curso de Pedagogia e a universitarização do magistério no Brasil: das disputas pela formação docente à sua desprofissionalização. Educação e Pesquisa, São Paulo, v. 45, p. 1-18, 2019.

SAVIANI, D. Formação de professores: aspectos históricos e teóricos do problema no contexto brasileiro. Revista Brasileira de Educação, Rio de Janeiro, v. 14, n. 40, 2009.

TARTUCE, G. L. B. P. et al. Alunos do ensino médio e atratividade da carreira docente no Brasil. Cadernos de Pesquisa, São Paulo, v. 40, n. 140, p. 445-477, 2010.

\section{Kíssila Ferreira Magro da Silva (Brasil, Rio de Janeiro, Campos dos Goytacazes)} Prefeitura Municipal de Campos dos Goytacazes

Licenciada em Pedagogia pelo Instituto Superior de Educação Professor Aldo Muylaert (Isepam). Professora de educação infantil da rede municipal de Campos dos Goytacazes, Rio de Janeiro.

Lattes: http://lattes.cnpq.br/5227244502557284.

E-mail: kissilafmagro.km@gmail.com.

Carla Patrícia Quintanilha Corrêa (Brasil, Rio de Janeiro, Campos dos Goytacazes)
Instituto Superior de Educação Professor Aldo Muylaert (Isepam)
Doutora em Educação pela Universidade Federal de Juiz de Fora (UFJF) com pós-doutorado em
Educação pela UFJF. Professora do curso de licenciatura em Pedagogia do Instituto Superior de
Educação Professor Aldo Muylart (Isepam).
Lattes: http://lattes.cnpq.br/4655143704136513.
E-mail: carlapqcorrea@hotmail.com.

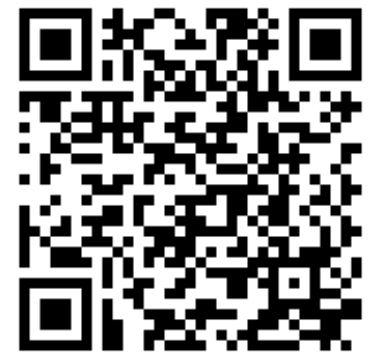

Recebido em 06 de agosto de 2019.

Aceito em 04 de novembro de 2019.

Educação \& Formação, Fortaleza, v. 5, n. 13, p. 59-78, jan./abr. 2020

DOI: https://doi.org/10.25053/redufor.v5i13.1468

http://seer.uece.br/redufor 